\title{
Benefit of a Contralateral Routing of Signal Device for Unilateral Cochlear Implant Users
}

\author{
Stefan Weder ${ }^{a, b}$ Martin Kompis ${ }^{a, b} \quad$ Marco Caversaccio ${ }^{a, b} \quad$ Christof Stieger $^{a-c}$ \\ ${ }^{a}$ Department of ENT, Head and Neck Surgery, Inselspital, University of Bern, and ${ }^{\mathrm{b}}$ ARTORG Center, University of \\ Bern, Bern, and ' Department of ENT, University Hospital Basel, Basel, Switzerland
}

\author{
Key Words \\ Cochlea implantation - Contralateral routing of signal \\ device $\cdot$ Head shadow effect
}

\begin{abstract}
Objective: To investigate objective and subjective effects of an adjunctive contralateral routing of signal (CROS) device at the untreated ear in patients with a unilateral cochlear implant $(\mathrm{Cl})$. Design: Prospective study of 10 adult experienced unilateral $\mathrm{Cl}$ users with bilateral severe-to-profound hearing loss. Speech in noise reception (SNR) and sound localization were measured with and without the additional CROS device. SNR was measured by applying speech signals at the untreated/CROS side while noise signals came from the front (S90N0). For SON90, signal sources were switched. Sound localization was measured in a 12-loudspeaker full circle setup. To evaluate the subjective benefit, patients tried the device for 2 weeks at home, then filled out the abbreviated Speech, Spatial and Qualities of Hearing Scale as well as the Bern benefit in single-sided deafness questionnaires. Results: In the setting S90N0, all patients showed a highly significant SNR improvement when wearing the additional CROS device (mean $6.4 \mathrm{~dB}, \mathrm{p}<0.001$ ). In the unfavorable setting S0N90, only a minor deterioration of speech understanding was noted (mean $-0.66 \mathrm{~dB}, \mathrm{p}=0.54$ ). Sound localization did not
\end{abstract}

improve substantially with CROS. In the two questionnaires, 12 of 14 items showed an improvement in mean values, but none of them was statistically significant. Conclusion: $\mathrm{Pa}-$ tients with unilateral $\mathrm{Cl}$ benefit from a contralateral CROS device, particularly in a noisy environment, when speech comes from the CROS ear side.

(c) 2014 S. Karger AG, Base

\section{Introduction}

Cochlear implants (CI) are a well-established and effective intervention for bilateral severe-to-profound sensorineural hearing loss [Bond et al., 2009]. A unilateral CI improves patient hearing significantly but the patient's situation is then comparable to single-sided deafness. Bilateral CI use brings a number of potential advantages compared to unilateral use such as the reduction of the head shadow effect, binaural summation, squelch effect, possibility of sound localization, having a backup device and ensuring that the better ear is implanted [van Hoesel and Tyler, 2003; Verschuur et al., 2005; Wightman and Kistler, 1997].

Reduction of the head shadow effect is widely reported as potentially the largest binaural advantage for bilateral cochlear implant listeners [Byrne, 1981; Murphy and

\section{KARGER 125\%}

2014 S. Karger AG, Basel

$1420-3030 / 14 / 0202-0073 \$ 39.50 / 0$

E-Mail karger@karger.com

www.karger.com/aud
Stefan Weder, MD

University Department of Otorhinolaryngology

Head and Neck Surgery, Inselspital Bern

$\mathrm{CH}-3010$ Bern (Switzerland)

E-Mail stefan.weder@insel.ch 
O'Donoghue, 2007; Verschuur et al., 2005]. Reduced hearing performance caused by the head shadow effect is most prominent when the sound is directed towards the untreated hard-of-hearing ear for a monaural listener. Attenuation of sound is greater at frequencies above approximately $1,500 \mathrm{~Hz}$ and less pronounced at lower frequencies below approximately $1,000 \mathrm{~Hz}$ [Pfiffner et al., 2011]. Typical attenuation is $3-7 \mathrm{~dB}$ for lower frequencies $(0.2-1 \mathrm{kHz})$ and $9-21 \mathrm{~dB}$ for higher frequencies $(2-8 \mathrm{kHz})$ [Algazi et al., 2002; Shaw, 1974]. The effect of binaural summation is attributed to the increased loudness associated with bilateral stimuli and to the redundancy of information in the stimuli at the two ears. This advantage improves the hearing threshold by approximately $5 \mathrm{~dB}$ at moderate sensation levels and up to $10 \mathrm{~dB}$ at high sensation levels [Byrne, 1981]. The hearing-impaired individuals obtain a similar degree of binaural summation to that of normal-hearing persons, both at threshold and suprathreshold levels [Byrne, 1981]. The squelch effect is obtained when speech and noise are perceived as spatially separate. As a result, detrimental effects of noise can be diminished to some extent, so the focus can be on the speech signal [Byrne, 1981]. Improved sound localization with bilateral CI was demonstrated in several studies [Nopp et al., 2004; van Hoesel et al., 2002; van Hoesel and Tyler, 2003; Verschuur et al., 2005]. However, Grantham et al. [2008] showed that some subjects with unilateral implantation could localize sounds better than chance level as well. One explanation is that these subjects learn to use monaural cues (level cues) based on loudness and frequency-dependent head shadow effects. However, performance was still significantly poorer than that reported in studies of bilaterally implanted subjects [Grantham et al., 2008]. Other studies could not confirm improvement in localization in unilaterally implanted subjects [ $\mathrm{Hol}$ et al., 2005; Verschuur et al., 2005].

Despite these advantages, there are some drawbacks and limitations concerning bilateral implantation. For instance, for medical reasons in some patients a CI is feasible only on one side. When financial sources for CI programs are limited, the responsible physician has to choose between unilateral and bilateral implantation [Summerfield et al., 2002]. Another challenge is sequential bilateral implantation. The longer the time span between the two surgeries, the poorer the result and patient satisfaction [Illg et al., 2013; Papsin and Gordon, 2008]. When the second implantation is delayed for several years, patients do often not appreciate the second CI because the first implant subjectively performs much better. This can lead to nonuse of the second device. A contralateral rout- ing of signal (CROS) hearing device providing a sound input at the contralateral ear could potentially be approved in these cases, if it improves hearing compared to a unilateral CI only.

The primary aim of this study was to prove efficacy of an elementary strategy to improve hearing in patients with bilateral severe-to-profound hearing loss and monaural CI. CROS is an adjunct which has been used for several years in patients with single-sided deafness. There is evidence from the literature that patients with singlesided deafness have a significantly better signal-to-noise ratio (SNR) when fitted with a CROS device than unaided patients [Hol et al., 2005; Lotterman and Kasten, 1971]. However, a CROS device has never been studied as an aid to patients with a unilateral CI, a condition which has some similarities to single-sided deafness. For this reason we investigated the objective and subjective benefit of a CROS device as aid to a CI in patients with bilateral deafness.

\section{Material and Methods}

\section{Subjects}

Thirteen unilateral CI users gave their informed consent to participate in this study. All of them were using the same CI processor (Opus2, Med-El, Austria). During evaluations there were 3 dropouts, 2 (No. 1 and 7) due to implantation in the CROSaided ear, 1 (No. 4) for personal reasons. Patient numbers $(2,3$, $5,6,8-13)$ refer to the 10 patients who completed all measurements. The study population had ages between 43 and 80 years, average age 59, and consisted of 4 men and 6 women. All subjects had binaural severe-to-profound sensorineural hearing loss (mean pure tone average \pm SD of the non-CI ear $112 \pm 14 \mathrm{~dB}$ ). Eight patients had their CI on the right, 2 patients on the left side. All participants had German as their mother tongue, attaining a performance of at least $90 \%$ at $60 \mathrm{~dB}$ SPL presentation level in the German speech test 'Freiburger Zahlen'. Patients were tested on average 6 years after insertion of the CI. Table 1 lists the patient demographics. Ethic approval for the study was granted by the Ethics Committee of the Canton of Bern (KEK: 165/11).

\section{Study Protocol}

The CROS device consisted of a hearing aid placed behind the ear with a wire connection to the contralateral side (Croslink Receiver CRX, Art. Nr. 052-3119-00001, Phonak Hearing Systems, Switzerland). An initially tested wireless CROS device was abandoned due to interference. Before starting tests we measured air conduction hearing thresholds with the $\mathrm{CI}$ alone to verify correct adjustment of the CI processor and calculated the patient's pure tone average hearing threshold.

All patients were measured twice: (1) with the CI alone and (2) in combination with the CROS device. Between the two visits, the patients used the CROS device in everyday life for at least 2 weeks. After 2 weeks, the patients filled out the abbreviated form of the 
Table 1. Patient demographics: gender, age, onset of hearing loss, CI experience, CI side, Freiburg numbers at 60 $\mathrm{dB}$, mean sound field threshold and pure tone average

\begin{tabular}{|c|c|c|c|c|c|c|c|c|}
\hline $\begin{array}{l}\text { Subject } \\
\text { No. }\end{array}$ & Gender & $\begin{array}{l}\text { Age, } \\
\text { years }\end{array}$ & Onset of HL & $\begin{array}{l}\text { CI exp., } \\
\text { years }\end{array}$ & CI side & $\begin{array}{l}\text { FN } 60 \\
\text { dB, \% }\end{array}$ & $\begin{array}{l}\text { MSFT, } \\
d B\end{array}$ & $\begin{array}{l}\text { PTA, } \\
\text { dB }\end{array}$ \\
\hline 2 & M & 80 & progressive & 6 & $\mathrm{~L}$ & 100 & 28 & 84 \\
\hline 3 & M & 77 & progressive & 2 & $\mathrm{R}$ & 100 & 37 & 93 \\
\hline 5 & $\mathrm{~F}$ & 64 & sudden & 6 & $\mathrm{~L}$ & 100 & 22 & 113 \\
\hline 6 & $\mathrm{~F}$ & 43 & progressive & 6 & $\mathrm{R}$ & 90 & 25 & 101 \\
\hline 8 & $\mathrm{~F}$ & 67 & sudden & 5 & $\mathrm{R}$ & 100 & 28 & 113 \\
\hline 9 & $\mathrm{~F}$ & 53 & progressive & 7 & $\mathrm{R}$ & 90 & 38 & 111 \\
\hline 10 & M & 53 & sudden & 16 & $\mathrm{R}$ & 100 & 37 & 119 \\
\hline 11 & $\mathrm{~F}$ & 43 & progressive & 4 & $\mathrm{R}$ & 90 & 30 & 114 \\
\hline 12 & $\mathrm{~F}$ & 47 & progressive & 3 & $\mathrm{R}$ & 90 & 37 & 114 \\
\hline 13 & M & 67 & progressive & 3 & $\mathrm{R}$ & 90 & 27 & 78 \\
\hline
\end{tabular}

$\mathrm{M}=$ male; $\mathrm{F}=$ female; mean age 59 years; $\mathrm{HL}=$ hearing loss $\mathrm{CI}$ exp. $=\mathrm{CI}$ experience, mean 6 years; $\mathrm{R}=$ right; $\mathrm{L}=$ left; FN = Freiburg numbers; MSFT = mean sound field threshold, free sound field with CI only, mean $29 \mathrm{~dB}$; PTA = pure tone average of non-CI ear, mean $112 \mathrm{~dB}$.

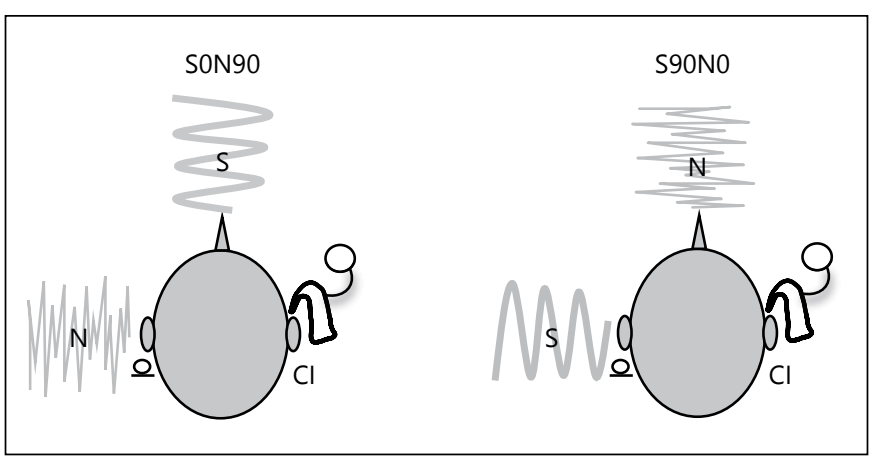

Fig. 1. SNR: spatial settings used in the study $(\mathrm{S}=$ Speech; $\mathrm{N}=$ noise). In the test setting S90N0 with the CROS device, an improvement of the SNR was expected.

Speech, Spatial and Qualities of Hearing Scale (SSQ) [Kiessling, 2011] as well as the Bern benefit in single-sided deafness questionnaire (BBSS) [Kompis et al., 2011]. These tools provide assessment of subjective benefit for speech perception, spatial hearing and quality of sound. Both questionnaires rely on a visual analog scale ranging from -5 to +5 . Positive values indicate a better quality of life with the CROS device, negative values a quality inferior to the exclusive use of a unilateral CI.

Audiological measurements were carried out during varying test settings (see below) and consisted of two parts: speech understanding in noise (Comité Consultatif International Télégraphique et Téléphonique, CCITT) and sound localization. The SNR was measured in two different spatial settings, as shown schematically in figure 1. In the setting S90N0, the target signal was emitted by the loudspeaker contralaterally to the CI, both with and without support of the ear by a CROS device, whereas noise was presented through a loudspeaker in front of the listener. In the setting S0N90, the positions of noise and target signal were switched to represent

Cochlear Implant and CROS an unfavorable situation for the use of a CROS device. We used the Oldenburger Sentence Test in the German language as adaptive speech in noise test [Wagener et al., 1999]. Noise level (CCITT) was held constant at $65 \mathrm{~dB}$ throughout all tests. Each subject started with 1 training list, which was not analyzed. Then, 2 lists of 30 sentences each were administered for each combination of spatial setting. From these results the averaged SNR was calculated. Sound localization was tested in a setup with 12 loudspeakers (JBL Control 1 PRO, Harman International Industries Inc.) equally distributed with 30 -degree azimuth angles in a full circle (radius of $1 \mathrm{~m}$ ) with the patient's head position in the center. Directional hearing measurements were carried out with a narrow-band noise burst of $200 \mathrm{~ms}$ duration and center frequencies of 500 and 3,150 Hz. The low frequency stimulation was chosen as it is more sensitive to interaural time difference, whereas the higher frequency stimulation is more sensitive to the interaural level difference [Humes et al., 1980; Wightman and Kistler, 1997]. The third stimulus was one randomly chosen sentence from the Oldenburger Sentence Test without noise signal. To avoid a level cue [Kumpik et al., 2010], the signal volume of $70 \mathrm{~dB}$ was randomly altered by $\pm 5 \mathrm{~dB}$. To register sound localization as indicated by the patient, a pointer method with $\mathrm{Mi}$ crosoft Kinect ${ }^{\mathrm{TM}}$ sensor technology was used: during test procedures the patient pointed his arm towards the direction of the perceived auditory event. The Kinect detected the direction of arm movement towards the perceived loudspeaker. As the $95 \%$ confidence interval for correct sound localization is below $20^{\circ}, 12$ loudspeakers, each covering an angle of $30^{\circ}$, enabled the reliable use of this system for our study.

\section{Results}

\section{Speech Recognition}

In the SNR test we compared the results of CI alone versus CI with additional CROS device, both in the test 


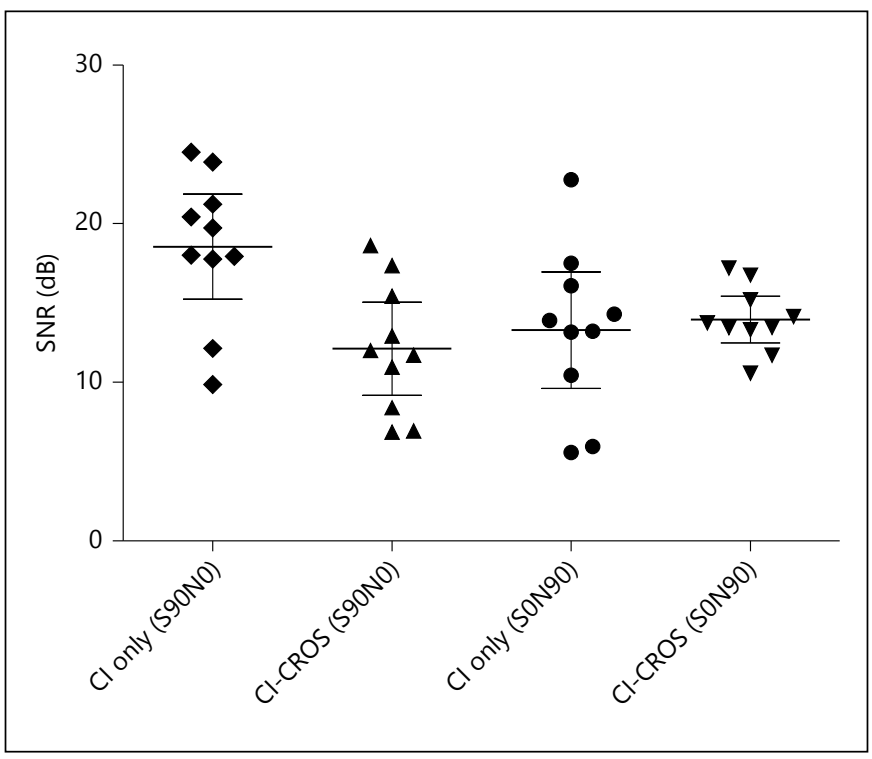

Fig. 2. Speech reception threshold in 4 different settings. Lines show the median value with $95 \%$ confidence interval. In the setting S90N0 CI-CROS, the SNR was significantly improved by $6.4 \mathrm{~dB}$ (mean value, $\mathrm{p}>0.001$ ). In the setting S0N90 CI-CROS, there was a deterioration of $-0.66 \mathrm{~dB}$ (mean value) compared to $\mathrm{CI}$ only.

settings of S90N0 and S0N90 (fig. 2). In the setting S90N0 (signal from the side) and CI supported by contralateral CROS, the SNR threshold improved significantly, i.e. on average by $6.43 \mathrm{~dB}(\mathrm{p}<0.001,95 \%$ confidence interval 3.63-9.28 dB). In the setting S0N90 (noise applied at the side of the CROS device), there was a deterioration of speech understanding of $-0.66 \mathrm{~dB}(95 \%$ confidence interval -4.1 to $2.78 \mathrm{~dB}$ ) with the additional CROS (compared to CI only), which was not statistically significant ( $\mathrm{p}=0.54,1$-way ANOVA). In 1 single subject (No. 2), the improvement in situation S90N0 $(3 \mathrm{~dB})$ was less than the deterioration in situation S0N90 (6.1 dB) when using a CROS device. At the same time this was the best performer at absolute SNR values in speech reception threshold.

The difference in SNR between both hearing conditions (S90N0 and S0N90) was significantly smaller ( $p<$ 0.01 , Wilcoxon matched-pairs signed-rank test) when using the CROS device $(-1.84 \mathrm{~dB})$ compared to the CI only $(5.26 \mathrm{~dB})$.

\section{Sound Localization}

Figure 3 shows the results of sound localization for the three listening conditions $(500 \mathrm{~Hz}$ narrow-band noise, $3,150 \mathrm{~Hz}$ narrow-band noise, speech signal) with and without CROS for all 10 subjects. In each diagram the stimulation angle versus the indicated angle of the subject is shown. The size of the circles depends on the total amount pointing to a given stimulation angle. In case of optimal localization abilities, we would expect a diagonal straight line with a slope of $45^{\circ}$, starting at point -150 / -150 and ending at $180 / 180$ with identical bubble sizes. The 2 patients in our study with a CI on the left side were side corrected so that all data could be integrated in the same figure.

There was a clustering of perceived signals on the side of the CI: using unilateral CI only, most signal sources were localized at around $90^{\circ}$ azimuth. A tendency of a second cluster could be observed for $3,150 \mathrm{~Hz}$ and speech signals at $30^{\circ}$ azimuth. With an additional CROS device, more responses were shifted to $0^{\circ}$ azimuth, particularly for $3,150 \mathrm{~Hz}$ and speech signals.

Mean angular errors with and without a CROS device were $88^{\circ}\left(\mathrm{SD} \pm 6^{\circ}\right)$ and $90^{\circ}\left( \pm 6^{\circ}\right)$ for $500 \mathrm{~Hz}, 86^{\circ}\left( \pm 7^{\circ}\right)$ and $83^{\circ}\left( \pm 6^{\circ}\right)$ for $3,150 \mathrm{~Hz}$ and $86^{\circ}\left( \pm 8^{\circ}\right)$ and $90^{\circ}\left( \pm 6^{\circ}\right)$ for speech, respectively.

\section{Patient Outcome Measures}

Most of BBSS and SSQ items (12 of 14) showed an improvement in the mean value (fig. 4,5 ), but none of them was statistically significant. In the BBSS, 'conversation in a car' (question 6) and 'sound localization' (question 9) were most prominent. In the SSQ questionnaire the most subjective improvement with an additional CROS device was in the section 'hearing effort' (fig. 5). 'Speech understanding in noise' and 'speech hearing' were rated as the poorest items in the BBSS (mean -0.3) and in the SSQ (mean-0.01), respectively.

Neither BBSS nor SSQ tests showed a significant correlation with the SNR, the Freiburg numbers at $60 \mathrm{~dB}$ or the mean sound field threshold with unilateral CI only.

\section{Discussion}

We investigated a CROS device as an adjunct to monaural CI in patients with bilateral severe-to-profound sensorineural hearing loss. The CROS device can be used immediately, requiring virtually no adjustment. There is no need for an additional surgery, and compared to a bilateral CI a CROS device is smaller and therefore more discrete. In this study, we investigated the subjective and objective benefits of an adjunctive CROS device. 


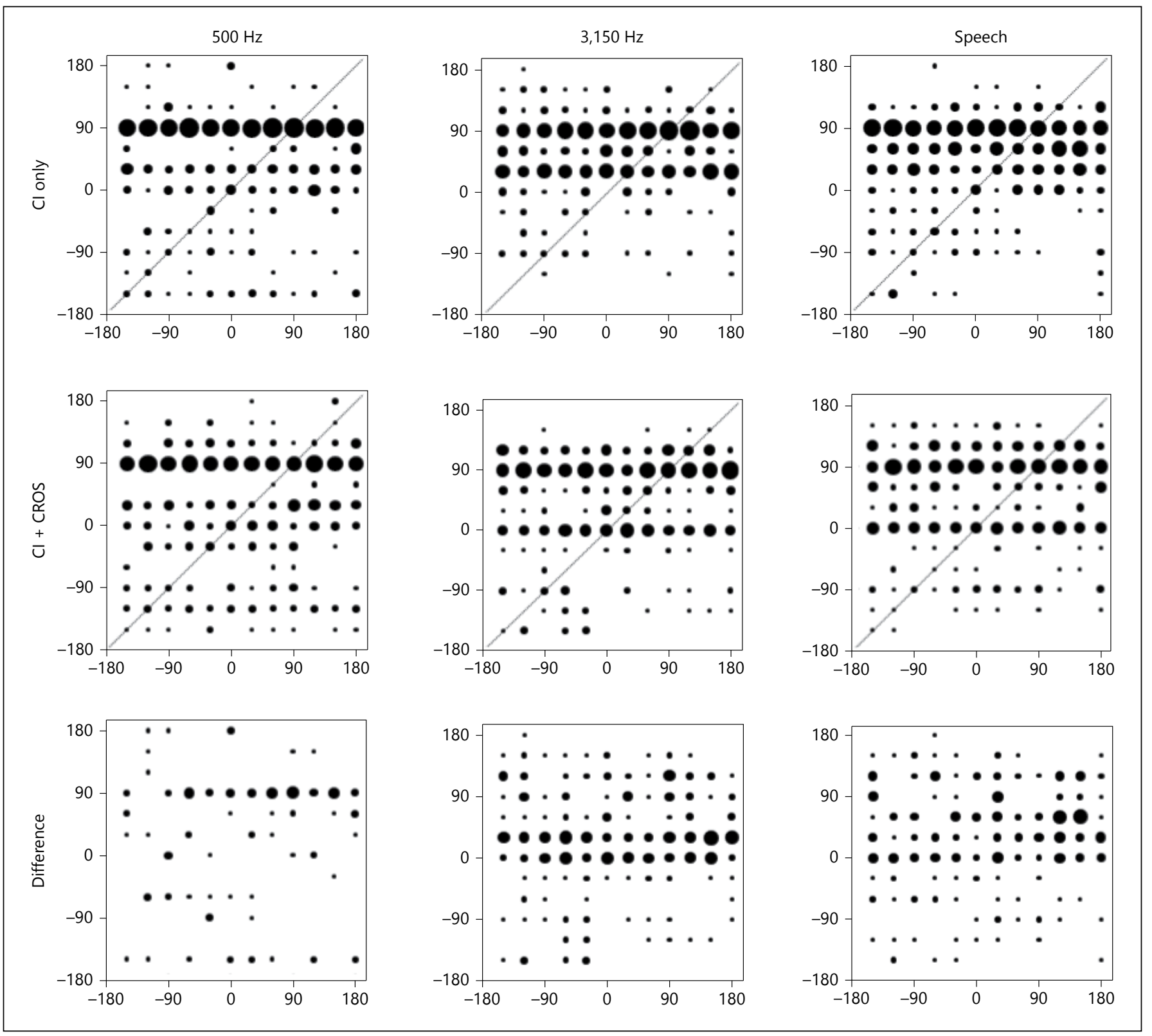

Fig. 3. Sound localization with CI only (upper row), with the CROS device (middle row) and the difference of the two in sound localization for $500 \mathrm{~Hz}$ (left column), 3,150 Hz (middle column) and speech signals (right column). The $\mathrm{x}$-axis represents the azimuth degree of the presented signal, the $y$-axis the azimuth degree point-

In speech recognition we could measure a highly significant improvement of the SNR for our patients. On average the SNR threshold was $6.4 \mathrm{~dB}$ lower with the CROS (1-way ANOVA in situation S90N0: $\mathrm{p}<0.001$ ). This effect has mainly to be explained by the diminished head shadow effect and to some extent to the squelch effect [Verschuur et al., 2005]. Binaural summation is ab-

Cochlear Implant and CROS ed out by the patient. The size of the circles depicts the total amount of pointing for the presentation angle. Black circles represent the results of this study, the black dotted diagonal line a hypothetical perfect sound localization.

sent in this situation as the same ear processes the information [Byrne, 1981].

In the unfavorable situation S0N90, there was a deterioration of the speech reception threshold of $-0.66 \mathrm{~dB}$ when using the additional CROS device, which was not statistically significant (S0N90: mean SNR CI only 13.1 $\mathrm{dB}$; CI-CROS 13.8; 1-way ANOVA, $\mathrm{p}=0.54$ ). It is known 


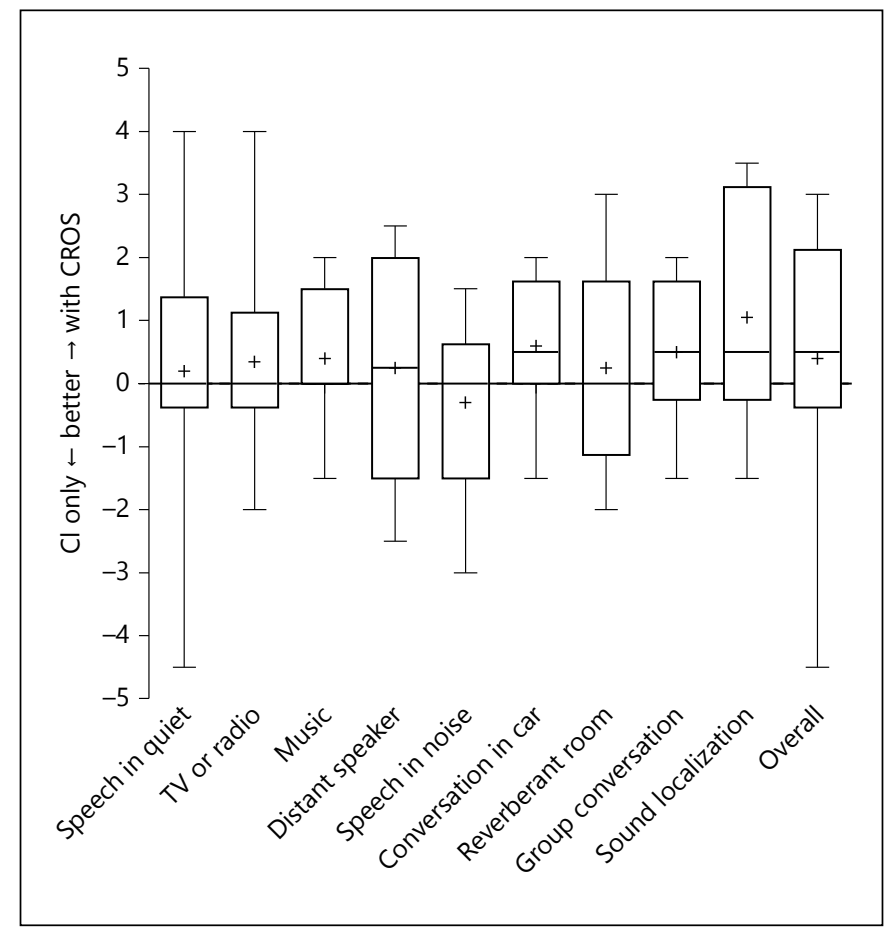

Fig. 4. Distribution of all subjects' answers for the BBSS questionnaire comparing the use of CI only and CI with the additional CROS device. Boxplots show medians, quartiles (boxes), minima, maxima and mean $(+)$ values.

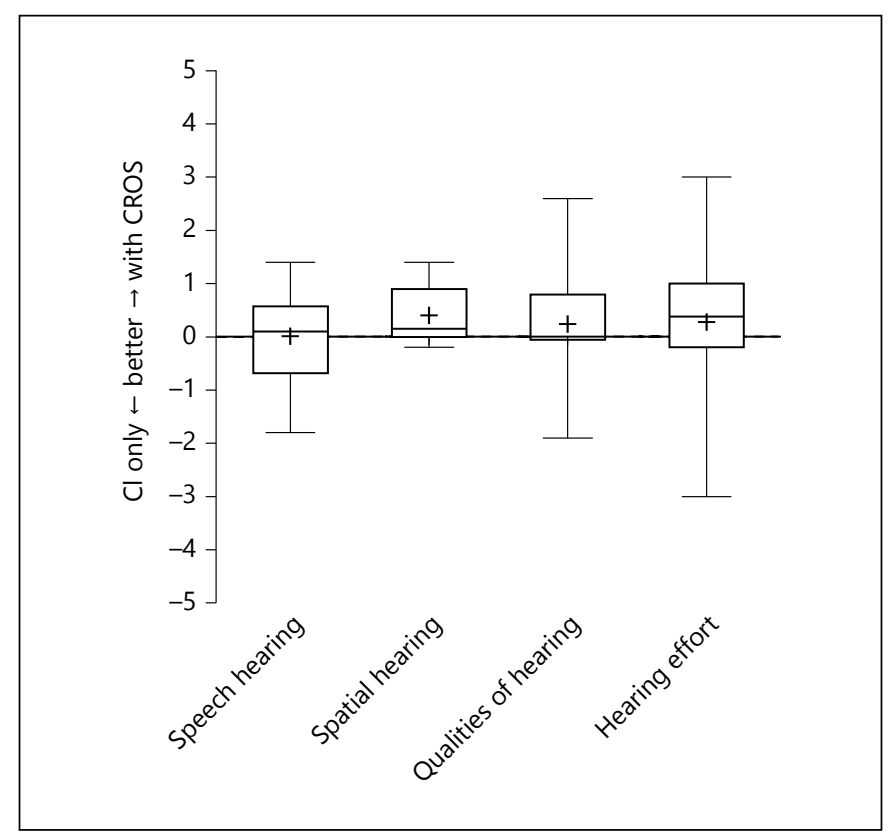

Fig. 5. Distribution of all subjects' answers for the SSQ questionnaire comparing the use of CI only and CI with the additional CROS device. Boxplots show medians, quartiles (boxes), minima, maxima and mean $(+)$ values. that CROS devices can lead to a deterioration in situation S0N90. A potential reason for the nonsignificant value in our study could be the spread of results. In the situation CI only S0N90, there was a prominent outlier (subject No. 12; SNR S0N90: $23.5 \mathrm{~dB}$ ). In other studies that evaluated the effect of a bone-anchored hearing aid in singlesided deafness (which is a similar situation to our 1-sided CI patients), deterioration in situation S0N90 was -0.7 to $-2.5 \mathrm{~dB}$ [Bosman et al., 2003; Hol et al., 2004; Linstrom et al., 2009; Pfiffner et al., 2011]. Our value of -0.66 lies at the bottom end of the scale of the quoted studies. In all 4 bone-anchored hearing aid studies, as in our study, the effect of reduction of the head shadow effect in situation S90N0 was always greater than the amplification of noise in situation S0N90.

Use of the CROS device did not substantially improve sound localization abilities. This result corresponds with those of previous studies [Hol et al., 2010; Verschuur et al., 2005]. We could not confirm the results of Grantham et al. [2008], where some subjects had still localization abilities with $1 \mathrm{CI}$ only, perhaps because these authors did not vary randomly the signal volume. Most of the responses in our study group were pointed to the 90-degree azimuth, which corresponds to the side of the CI. With the CROS device the perception of signals was shifted slightly to the 0 -degree azimuth and the CROS ear. Patients with a CROS device tend to classify perceived sound signals mainly from two directions: signals perceived from the CI side $\left(90^{\circ}\right)$ and signals from the front $\left(0^{\circ}\right)$. This could explain the subjective better localization abilities in the BBSS. However, there is no obvious relation between stimulation angle and one of the two conditions, which means that besides localization there is also no objective improvement in lateralization.

In subjective patient outcome measurements, 12 of 14 items showed an improvement in mean value. Only 'speech understanding in noise' (BBSS) and 'speech hearing' (SSQ) had a negative mean. This finding is not consistent with our objective results of the Oldenburg Sentence Test, where patients clearly showed a profit in the favorable situation $\mathrm{S} 90 \mathrm{~N} 0$ and only a minor deterioration in the unfavorable situation S0N90. This mismatch was already described by Kompis et al. [2011], who investigated crucial factors influencing the decision for a boneanchored hearing aid device in unilateral deafness. There was no correlation between the threshold of the SNR, the result of the Freiburg numbers or mean sound field threshold with the scores of the questionnaires. Therefore questionnaires evaluating the satisfaction with a CROS device seem to be useful to assess the benefit. We noted 
that patients who were very satisfied with the CROS device and wanted to continue using it had high scores in the SSQ and BBSS. Three patients of our study were very satisfied with the additional CROS device, 5 patients saw an improvement in some situations during daily life and 2 patients were dissatisfied with the device. The cable around the neck disturbed half of the patients. This point could be overcome by using a wireless device.

CROS devices in combination with a CI can be fitted quickly without adjustments. Patients can therefore evaluate the subjective benefit of the device very easily. We assume that the main advantage of an additional CROS device is the reduction of the head shadow effect. This can be important in situations such as holding a conversation while driving. Depending on the position of the speaker, a CROS device can facilitate conversation substantially as emphasized by our BBSS questionnaire results.

In source localization tests, patients were instructed to always face towards the loudspeaker in front $\left(0^{\circ}\right.$ azimuth), which does not correspond to behavior in real life. Subjects with a significant asymmetric hearing loss such as single-sided deafness tend to turn the better ear towards a speaker instead of continuously facing the speaker. This compensatory behavior adapted to deafness is potentially reduced when using the CROS device because the difference of speech intelligibility ( $\Delta \mathrm{CI}$ only $-1.84 \mathrm{~dB}, \Delta \mathrm{CI}$ CROS $5.26 \mathrm{~dB}$ ) between different listening conditions (S0N90-S90N0) is less pronounced.

In this study we used a technically inappropriate CROS device with a cable connection to the CI. Furthermore the cable around the neck diminished user acceptance. CROS devices with wireless connection and no disturbance to the CI output are preferable. Another limitation might be the relatively small bandwidth $(200-4,000 \mathrm{~Hz})$ of the CROS device. Multiple microphone technology with adaptive beam-forming has been shown to improve speech intelligibility for CIs and conventional hearing systems in noisy environments [Hersbach et al., 2013; Kompis and Dillier, 2001]. Modern conventional hearing aids are able to use the microphone signals for optimizing the setting of bilateral hearing devices [Ricketts and Picou, 2013]. In this study we showed that the transmission of the microphone signals, without a sophisticated sound processing, already compares favorably to the unilateral CI condition. Intelligent preprocessing of the microphone signal and communication between CI and CROS device might improve hearing and speech perception further.

\section{Conclusion}

Patients with bilateral severe-to-profound sensorineural hearing loss and only a unilateral CI may benefit from a contralateral CROS device. Eligible candidates include patients who cannot profit for medical or financial reasons from a second CI as well as late implantees, who do not tolerate their second CI well. In our study all of the patients showed highly significant improvement of their SNR threshold with the CROS device.

\section{Disclosure Statement}

Conflicts of interest and source of funding: none.

\section{References}

-Algazi VR, Duda RO, Duralswami R, Gumerov Grantham DW, Ricketts TA, Ashmead DH, Labadie NA, Tang Z: Approximating the head-related transfer function using simple geometric models of the head and torso. J Acoust Soc Am 2002;112:2053-2064.

Bond M, Mealing S, Anderson R, Elston J, Weiner G, Taylor RS, Hoyle M, Liu Z, Price A, Stein $K$ : The effectiveness and cost-effectiveness of cochlear implants for severe to profound deafness in children and adults: a systematic review and economic model. Health Technol Assess 2009;13:1-330.

Bosman AJ, Hol MK, Snik AF, Mylanus EA, Cremers CW: Bone-anchored hearing aids in unilateral inner ear deafness. Acta Otolaryngol 2003;123:258-260.

Byrne D: Clinical issues and options in binaural hearing aid fitting. Ear Hear 1981;2:187-193. RF, Haynes DS: Localization by postlingually deafened adults fitted with a single cochlear implant. Laryngoscope 2008;118:145-151.

- Hersbach AA, Grayden DB, Fallon JB, McDermott HJ: A beamformer post-filter for cochlear implant noise reduction. J Acoust Soc Am 2013;133:2412-2420.

Hol MK, Bosman AJ, Snik AF, Mylanus EA, Cremers CW: Bone-anchored hearing aid in unilateral inner ear deafness: a study of 20 patients. Audiol Neurootol 2004;9:274-281.

-Hol MK, Bosman AJ, Snik AF, Mylanus EA, Cremers CW: Bone-anchored hearing aids in unilateral inner ear deafness: an evaluation of audiometric and patient outcome measurements. Otol Neurotol 2005;26:9991006.
Hol MK, Kunst SJ, Snik AF, Cremers CW: Pilot study on the effectiveness of the conventional CROS, the transcranial CROS and the BAHA transcranial CROS in adults with unilateral inner ear deafness. Eur Arch Otorhinolaryngol 2010;267:889-896.

Humes LE, Allen SK, Bess FH: Horizontal sound localization skills of unilaterally hearing-impaired children. Audiology 1980;19:508-518.

Illg A, Giourgas A, Kral A, Buchner A, LesinskiSchiedat A, Lenarz T: Speech comprehension in children and adolescents after sequential bilateral cochlear implantation with long interimplant interval. Otol Neurotol 2013;34:682-689.

Kiessling J, Grugel L, Meister H, Meis M: German translations of the questionnaires $\mathrm{SADL}$, ECHO and SSQ and their evaluation. Z Audiol/Audiol Acoust 2011;50:6-16. 
Kompis M, Dillier N: Performance of an adaptive beamforming noise reduction scheme for hearing aid applications. I. Prediction of the signal-to-noise-ratio improvement. J Acoust Soc Am 2001;109:1123-1133.

Kompis M, Pfiffner F, Krebs M, Caversaccio MD: Factors influencing the decision for BAHA in unilateral deafness: The Bern benefit in single-sided deafness questionnaire. Adv Otorhinolaryngol 2011;71:103-111.

Kumpik DP, Kacelnik O, King AJ: Adaptive reweighting of auditory localization cues in response to chronic unilateral earplugging in humans. J Neurosci 2010;30:4883-4894.

Linstrom CJ, Silverman CA, Yu GP: Efficacy of the bone-anchored hearing aid for single-sided deafness. Laryngoscope 2009;119:713720 .

Lotterman SH, Kasten RN: Examination of the CROS type hearing aid. J Speech Hear Res 1971;14:416-420.

Murphy J, O’Donoghue G: Bilateral cochlear implantation: an evidence-based medicine evaluation. Laryngoscope 2007;117:1412-1418.
Nopp P, Schleich P, D’Haese P: Sound localization in bilateral users of Med-El combi 40/40+ cochlear implants. Ear Hear 2004;25:205214.

Papsin BC, Gordon KA: Bilateral cochlear implants should be the standard for children with bilateral sensorineural deafness. Curr Opin Otolaryngol Head Neck Surg 2008; 16 : 69-74.

- Pfiffner F, Kompis M, Flynn M, Asnes K, Arnold A, Stieger C: Benefits of low-frequency attenuation of BAHA ${ }^{\circledR}$ in single-sided sensorineural deafness. Ear Hear 2011;32:40-45.

Ricketts TA, Picou EM: Speech recognition for bilaterally asymmetric and symmetric hearing aid microphone modes in simulated classroom environments. Ear Hear 2013;34:601609.

Shaw EA: Transformation of sound pressure level from the free field to the eardrum in the horizontal plane. J Acoust Soc Am 1974;56:18481861.
Summerfield AQ, Marshall DH, Barton GR, Bloor KE: A cost-utility scenario analysis of bilateral cochlear implantation. Arch Otolaryngol Head Neck Surg 2002;128:1255-1262.

Van Hoesel R, Ramsden R, Odriscoll M: Sound-direction identification, interaural time delay discrimination, and speech intelligibility advantages in noise for a bilateral cochlear implant user. Ear Hear 2002; 23:137-149.

Van Hoesel RJ, Tyler RS: Speech perception, localization, and lateralization with bilateral cochlear implants. J Acoust Soc Am 2003;113: 1617-1630

- Verschuur CA, Lutman ME, Ramsden R, Greenham P, O'Driscoll M: Auditory localization abilities in bilateral cochlear implant recipients. Otol Neurotol 2005;26:965-971.

Wagener K, Kühnel V, Kollmeier B: Entwicklung und Evaluation eines Satztests in deutscher Sprache. I. Design des Oldenburger Satztests. Z Audiol 1999;38:4-15.

Wightman FL, Kistler DJ: Monaural sound localization revisited. J Acoust Soc Am 1997;101: 1050-1063. 